\title{
SMART BED DESIGN FOR SENIOR CITIZENS : A QUALITY FUNCTION DEPLOYMENT APPROACH
}

\author{
Jiao Chen \\ Shanghai University, P.R.China \\ Xiaosong Zheng \\ Shanghai University, P.R.China \\ Jiehui Jiang \\ Shanghai University, P.R.China
}

\begin{abstract}
With the increasing number of senior citizens, the quality of their life arises more attention. Smart beds can be used as intelligent tools to easy their life. Besides, as the user-oriented care becomes more dominant recently in healthcare industry, especially for the elderly, Quality Function Deployment (QFD) is used for smart bed's design. As a quality control method, QFD is a systematic process to translate "voice of customers" into technical requirements by focusing more on users' needs and could contribute to achieve customers' satisfaction better. By house of quality process, this article points out that in order to meet customers' demands, designers should think more on sleep function and postural adjustment.
\end{abstract}

Keywords: Quality Function Deployment, Smart bed, Senior citizens.

\section{JEL code: Z00}

\section{Introduction}

Based on UN demographic survey, it is expected that the population of senior citizens aging over 60 will reach to $21.8 \%$ in the middle of twenty-one century (Lutz et al., 2008). With the rapid growth of senior citizens' population, people focus more on their needs, striving for a more convenient and comfortable lifestyle to easy their life. Given people spending most of the time in bed, smart bed derived from senior citizens' health care needs has gradually attracted people's attention.

In addition to improving quality of healthcare, many countries try to provide more patient-oriented healthcare (Lee et al., 2015). Tu et al. (2011) cite that one reason for new product development's failure is its process being technology-driven instead of customer demand-driven. User-centered design (UCD) principle has been applied into new product development and it also should be considered in designing senior citizens' products. Kazemi \& Kajonius (2017) state aimed at improving senior citizens' satisfaction, user-oriented care 
has become the mainstream of contemporary elderly care in many western welfare states. User-centered design in healthcare industry or user-oriented care is characterized by putting users' demands, preferences, wants and limitations in the center of caregiving.

As a systematic process, Quality Function Deployment (QFD) is used for services and products design in view of customer needs. Developed by Akao in Japan, QFD is a method to convert user's needs into technical requirements during each step of producing products and delivering services (Chan \& $\mathrm{Wu}, 2002$ ). Quality function deployment (QFD) has the following advantages: firstly it pays more attention to "customers' voice", has a better understanding of customers' needs and helps to fulfill user's expectations; secondly by a systematic prioritization, it contributes to identify process improvements, which means QFD is an effective way to identify aspects that are vital for users; furthermore, QFD is also a critical method for quality control (Hunt \& Killen, 2004; Gremyr \& Raharjo, 2013; Moores, 2006; Buttigieg et al., 2016; Lim \& Tang, 2000). Applying QFD in healthcare services or products could reveal users' requirements, promote the modifications of vital services and thus fulfill users' satisfaction (Lee et al., 2015).

There are increasing researches concerning QFD application in healthcare industry (Gremyr \& Raharjo, 2013). The application of QFD in this area attempts to better understand users' needs and figures out the best process to meet needs. QFD is utilized to improve the quality of medical devices maintenance systems in Prince Hamzeh hospital for achieving users' satisfaction (Al-Bashir et al., 2012). Gremyr \& Raharjo (2013) study the application of QFD in a design for six sigma project to propose an in-patient medication process for reducing the probability of adverse drug events. By QFD and logical framework approach, Buttigieg et al. (2016) build a patient-focused analytical framework for improving care quality of accident and emergency in Maltese hospital. Lee et al. (2015) put forward a fuzzy QFD approach in healthcare industry for supporting related decision-making process. QFD has also been integrated into total quality management (Chien \& Su, 2003; Hunt \& Xavier, 2003; Walden, 2004). Lim \& Tang (2000) propose a QFD-led model for total quality healthcare.

For this article, the authors using QFD method mainly aims at capturing and prioritizing the elderly's requirements for smart bed.

\section{The process of House of Quality (HoQ)}

As a quality tool, Quality Function Deployment (QFD) helps to reflect voice of customer (VoC) into technical requirements, which makes new product satisfying users' real demand (Jaiswal, 2012). As the core of QFD, the House of Quality (HoQ) is a matrix consisting of some interconnected sub-parts (Al-Bashir et al., 2012). QFD system has several phases while for this paper's purpose, only one process of HoQ is illustrated to identify what smart beds' designer should value in order to meet user's needs at the maximum degree. QFD is mainly processed by House of Quality (HoQ) in Figure 1 (Zheng \& Pulli, 2007). 

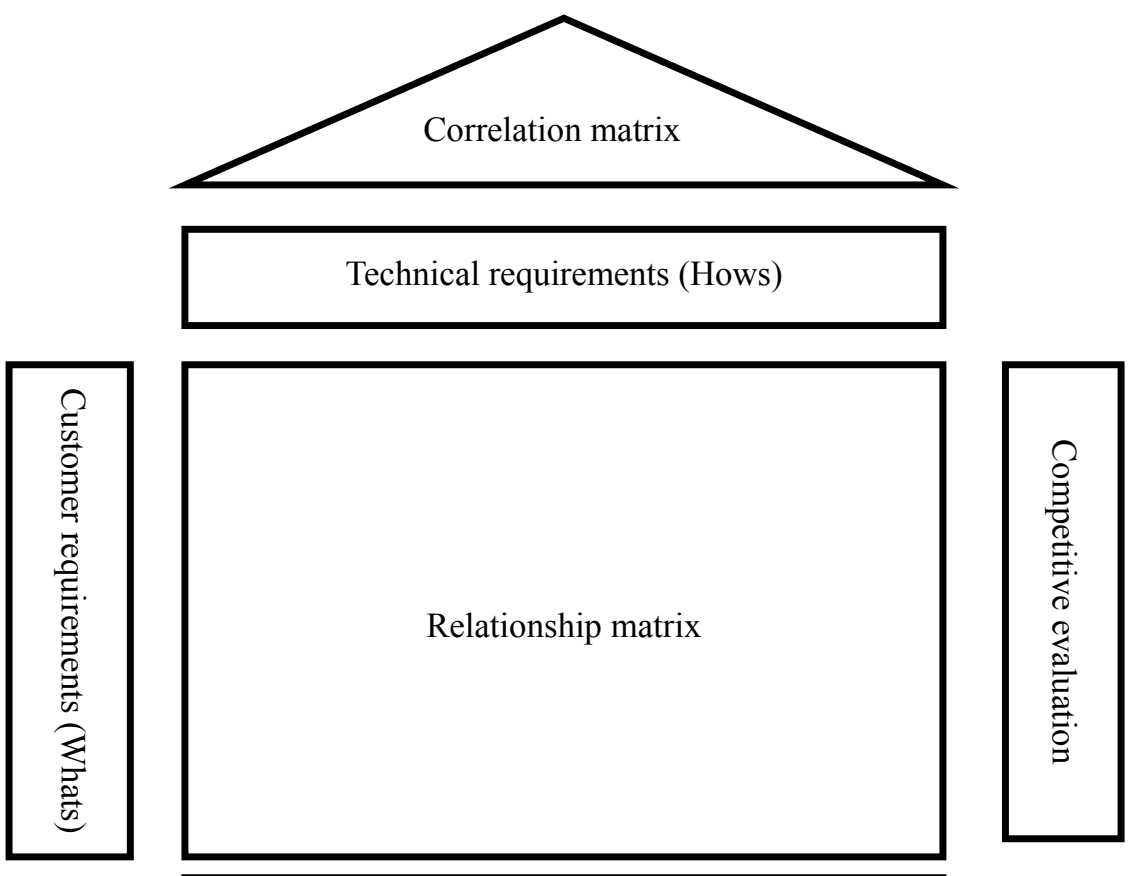

Importance weighting

Target values

Technical evaluation

Figure 1. House of Quality (HoQ)

The left side of HoQ is the customer requirements or known as the voice of customer (VoC), which is the list of "what" customers want.

Technical requirements are characterizes of product from designers' points in order to meet customers' needs. It means how customer requirements be satisfied and undertakes the voice of company. The translation from customer requirements to technical requirements is an important part of HoQ and multiple technical requirements should be made to correspond to one customers' requirement (Al-Bashir et al., 2012).

Besides, relationships between customer requirements and technical requirements are quantified in relationship matrix in the middle part of HoQ. The scale is 1-3-5 meaning week, medium and strong respectively.

The top triangle part is correlation matrix illustrating relationship among technical requirements and their impacts on each other. The article does not discuss this part for simplicity.

Right side of HoQ is competitive evaluation. It presents users' view on existing products and 
provides comparison between new products and its similar products in present market.

Importance weighting is calculated based on relationship matrix and after setting up target values, the most important technical requirement in service design will be known. The bottom of HoQ is technical evaluation (Zheng \& Pulli, 2007; Shahin, 2016; Al-Bashir et al., 2012)

\subsection{Confirmation of customer requirements}

One important step of QFD is to understand users' needs and requirements. In order to get effective and accurate data, the user group members go to hospitals, nursing homes and other related places to get along with the elderly for a whole day.

\subsubsection{Multi-scene observation}

Without disturbing normal rest of senior citizens, the user group members go to hospital, nursing home and family home separately to observe their activities in three different scenes from 8:00 AM to 18:00 PM. Observers are very patient and strive to record the elderly's daily activities as much as possible even subtle activities. They should pay attention to movements of the observed people and figure out roots of the suffering even if the senior citizens just "ouch" a few times. At the same time, observers have to record details in a pre-designed Excel (Table 1 is part of the designed Excel). During the observation, many problems are found. For example, the families' nursing workers do not often help the senior citizens convert their body. Besides, senior citizens living in hospitals or nursing homes are very lonely for not seeing their offspring.

After making an electronic record, the user group members analysis the percentage of each movement in a day (Table 2) and filter out ten important needs: solving the problem of leg hemp, leg cramps and waist trapped; changing diapers; breathable cooling in summer; warm in winter; adjust the height of bed; massage; the connection between bed and wheelchair; eating; entertaining; alarm.

Table 1. Example of the Pre-designed Excel

\begin{tabular}{|c|l|l|l|l|}
\hline & $08: 00-08: 05$ & $08: 05-08: 10$ & $08: 10-08: 15$ & $08: 15-08: 20$ \\
\hline What the elderly do & & & & \\
\hline $\begin{array}{c}\text { What is the specific } \\
\text { behavior of the elderly }\end{array}$ & & & & \\
\hline $\begin{array}{c}\text { How family } \\
\text { member/care worker } \\
\text { help the elderly do }\end{array}$ & & & & \\
\hline $\begin{array}{c}\text { What products/objects } \\
\text { appear in the scene }\end{array}$ & & & & \\
\hline
\end{tabular}


Table 2. Daily living observations of the senior citizens

$\begin{array}{cc}\text { Activities } & \text { The percentage of a day } \\ \text { In bed } & 93.05 \\ \text { Side lying } & 15.97 \\ \text { Leaning in a wheelchair } & 6.94 \\ \text { Watching TV } & 6.94 \\ \text { Sunbathe } & 5.90 \\ \text { Midday rest } & 5.56 \\ \text { Talking with famlily member } & 4.17 \\ \text { Wiping the body \& Changing diapers } & 2.08 \\ \text { Fanning by family member } & 1.74 \\ \text { Drinking water through tube } & 0.70 \\ \text { Taking medicine } & 0.70 \\ \text { Wiping saliva by family member } & 0.70 \\ \text { Bedding by family member } & 0.70 \\ \text { The elderly moved to bed } & 0.35 \\ \text { Checking faeces \& urine } & 0.35 \\ \text { Eating through tube } & 0.35 \\ \text { Eating honey } & 0.35 \\ \text { Measuring body temperature } & 0.35\end{array}$

\subsubsection{Questionnaire research}

In order to check whether the filtered needs above are scientific and effective as well as identifying importance of the demands (scale from 1 to 5 , 1 means least importance), questionnaires are designed for senior citizens, family members and care workers. After the interview, ten quality needs are identified: Help to improve sleep quality; Good air permeability and cooling in summer; Warm in winter; Having a massage; Could swift between bed and wheelchair; Watching TV in bed; Handling Emergency conditions; Cost effective; Preventing bedsore; Assisting occupant turnover.

\subsection{Confirmation of technical requirements}

With the survey results of user group members, technical group members determine nine technical requirements based on the customer voice. In table 3, there are nine important technical requirements designed for smart beds. 
Table 3. Illustration of technical requirements

\begin{tabular}{|ll|l|}
\hline No. $\quad$ Technical requirements & \multicolumn{1}{c|}{ Illustration } \\
\hline 1 & Emergency function & It handles some emergency conditions \\
\hline 2 & Touch screen & Old people can watch TV by it \\
\hline 3 & Postural adjustment & It help to adjust the elderly's posture \\
\hline 4 & Docking device & It is the connection between bed and wheelchair \\
\hline 5 & Massage function & It is designed to massage body \\
\hline 6 & Temperature control & It controls the temperature of bed \\
\hline 7 & Auxiliary sleep function & To monitor sleep condition and improve it \\
\hline 8 & Physiological parameters detection & It can detect conditions of physiological parameters \\
\hline 9 & Good air permeability material & For cost effective and good air permeability \\
\hline
\end{tabular}

After the identification of quality requirements and technical requirements, the HoQ shown in figure 2 should be built.

\begin{tabular}{|c|c|c|c|c|c|c|c|c|c|c|c|}
\hline $\begin{array}{l}\text { Relationships: } \\
\text { - Strong -5 } \\
\text { () Medium -3 } \\
\text { ○ Weak -1 }\end{array}$ & 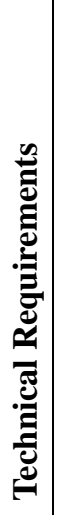 & 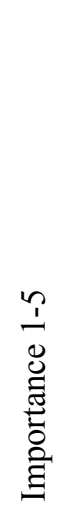 & 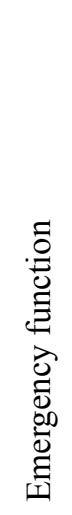 & 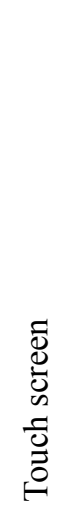 & 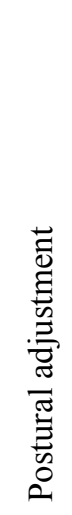 & $\begin{array}{l}0 \\
.0 \\
0 \\
0 \\
00 \\
. \Xi \\
0 \\
0 \\
0\end{array}$ & 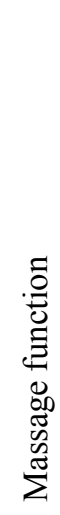 & 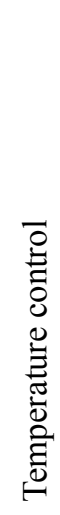 & 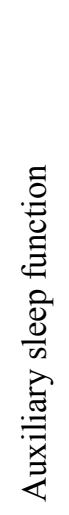 & 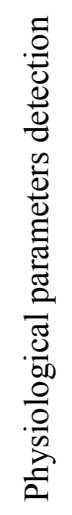 & 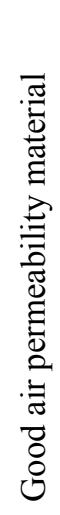 \\
\hline \multicolumn{12}{|l|}{ Quality Requirements } \\
\hline Help to improve sleep quality & & 5 & & ○ & (0) & & () & () & $\bullet$ & (0) & () \\
\hline $\begin{array}{l}\text { Good air permeability and } \\
\text { cooling in summer }\end{array}$ & & 3 & & ○ & & & & ○ & () & & $\bullet$ \\
\hline Warm in winter & & 3 & $\circ$ & $\circ$ & & & & $\bullet$ & (0) & $\circ$ & \\
\hline Could have a massage & & 4 & & $\circ$ & () & & $\bullet$ & & () & (a) & \\
\hline $\begin{array}{l}\text { Could swift between bed and } \\
\text { wheelchair }\end{array}$ & & 1 & & & & $\bullet$ & & & & & \\
\hline Watching TV in bed & & 2 & & $\bullet$ & ० & & & & & & \\
\hline Handling Emergency conditions & & 5 & $\bullet$ & & & & & & & (0) & \\
\hline Cost effective & & 1 & & & & & & & & & () \\
\hline Preventing bedsore & & 4 & & & () & $\circ$ & $\bullet$ & & & $\circ$ & ○ \\
\hline Assisting occupant turnover & & 3 & () & ○ & $\bullet$ & $\circ$ & & & () & & \\
\hline Absolute importance ranking & & & 37 & 28 & 56 & 12 & 55 & 33 & 64 & 49 & 37 \\
\hline Relative importance ranking & & & 5 & 7 & 2 & 8 & 3 & 6 & 1 & 4 & 5 \\
\hline
\end{tabular}

Figure 2: The HoQ for smart bed design 
The importance of customer quality requirements scaled from most valuable to least valuable by $5-1$ is listed in the figure above. Customer requirements are denoted by $X_{1,2,3 \ldots 9,10}$ while the strength of relationship between customer and technical needs from high to low is marked by $\bullet, \bigcirc$, o which represents 5,3,1 respectively and denoted by $\mathrm{Y} . Y_{\ell, j}$ means the connection between customer requirement $i$ and technical requirement $\mathfrak{j}$. Thus, the absolute importance score of each technical requirement $W_{j=1,2, \ldots, 3,9}$ is expressed by follows:

$$
W_{j}=\sum_{i=1}^{10} X_{i} \times Y_{i, 1}^{N}
$$

Both absolute and relative importance ranking have been calculated. It is known that auxiliary sleep function ranks higher which means designers should pay more attention to this function while designing smart beds. Postural adjustment in second place also should be taken seriously.

\section{Conclusion}

An increasing number of countries pay more attention to the healthcare industry and the concept of user-oriented care also becomes more and more popular and being dominant in service or product design. Given senior citizens spend most of their time in bed, smart bed is considered as an effective way to easy their life. With the principle of user-centered design, this article mainly uses the kernel of quality function deployment - the house of quality (HoQ) method to figure out what should be prioritized in designing smart bed. By multi-sense observations and questionnaire research, the user group members identify ten smart beds' customer requirements and the technical group members translate these customer requirements to technical requirements. By $\mathrm{HoQ}$, this paper points out that designers should focus more on auxiliary sleep function and postural adjustment in order to make smart bed really meets customers' demands.

\section{Acknowledgement}

This research is supported by Shanghai Committee of Science and Technology (16441906200) and Shanghai University education funding.

\section{References}

Al-Bashir, A., Al-Rawashdeh, M., Al-Hadithi, R., Al-Ghandoor, A. and Barghash, M. (2012) "Building Medical Devices Maintenance System through Quality Function Deployment", Jordan Journal of Mechanical and Industrial Engineering, vol. 6, no. 1, pp. 25-36.

Buttigieg, S. C., Dey, P. K. and Cassar, M. R. (2016) “Combined quality function deployment 
and logical framework analysis to improve quality of emergency care in Malta", International Journal of Health Care Quality Assurance, vol. 29, no. 2, pp.123-140.

Chan, L.K. \& Wu, M.L. (2002) "Quality function deployment: a literature review”, European Journal of Operations Research, vol. 143, no. 3, pp. 463-497.

Chien, T. K. \& Su, C. T. (2003) "Using the QFD concept to resolve customer satisfaction strategy decisions", International Journal of Quality and Reliability Management, vol. 20, no. 3 , pp.345-359.

Gremyr, I. \& Raharjo, H. (2013) "Quality function deployment in healthcare: a literature review and case study", International Journal of Health Care Quality Assurance, vol. 26, no. 2, pp.135-146.

Hunt, R. \& Killen, C. (2004). Best practice quality function deployment (QFD). Bradford, England: Emerald Group Pub.

Hunt, R. A. \& Xavier, F. B. (2003) “The leading edge in strategic QFD”. International Journal of Quality and Reliability Management, vol. 20, no. 1, pp. 56-73.

Jaiswal, E.S.(2012) “A case study on Quality Function Deployment (QFD)”. IOSR Journal of Mechanical and Civil Engineering, pp. 27-35.

Kazemi, A. \& Kajonius, P. (2017) "Variations in user-oriented elderly care: a multilevel approach”, International Journal of Quality and Service Sciences, vol. 9, no. 2, pp.138-147

Lee, C. K. M., Ru, C. T. Y., Yeung, C. L., Choy, K. L., Ip, W. H. (2015) “Analyze the healthcare service requirement using fuzzy QFD”, Computers in Industry, vol. 74, pp. 1-15.

Lim, P. C., Tang, N. K.H. (2000) "The development of a model for total quality healthcare", Managing Service Quality: An International Journal, vol. 10, no. 2, pp.103-111.

Lutz, W., and Sanderson, W. and Scherbov, S. (2008) "The coming acceleration of global population ageing”. Nature, pp.716-719.

Moores, B.M. (2006) "Radiation safety management in health care - the application of quality function deployment”, Radiography, Vol. 12 No. 4, pp. 291-304.

Shahin, A. (2016) “Quality Function Deployment: A Comprehensive Review”, ResearchGate, vol. 12 .

Tu, N., Zhang, T., He, Q. Y., Zhang, H. F. and Li, Y. H. (2011) "User-Centered Design in New Product Development: a case study in developing new sports earphone", Computer and Management (CAMAN), International Conference on. 
Walden, J. (2003) "Performance excellence: a QFD approach". International Journal of Quality and Reliability Management, vol. 20, no. 1, pp.123-133.

Zheng.X.S. \& Pulli.P. (2007) "Towards High Quality Mobile Service for Senior Citizens in Smart Living Environments". Multimedia and Ubiquitous Engineering, International Conference on, pp.164-170. 